\title{
AN EXPERIMENTAL STUDY OF BIAXIAL STRESS-STRAIN RELATIONS IN PLASTICITY*
}

\author{
By P. M. Naghdi and J. C. Rowley \\ Department of Engineering Mechanics, University of Michigan
}

(Received 20th May, 1954)

SUMMARY

EXPERImental results for ten tubular 24. S-T4 aluminium-alloy specimens which possessed severe initial anisotropy are reported. These variable-loading path tests, where tension alone was followed by torsion, permitted the determination of the initial shear modulus when twist began. The results are discussed with reference to both initial and strain-hardening anisotropy.

\section{INTRODUCTION}

Althougi considerable progress has been made in recent years in the development of isotropic theories of plasticity for strain-hardening materials (Prager 1948, 1949), relatively little is known about theories of plasticity which account for initial anisotropy and for such phenomena as the Bauschinger effect. This is not surprising, as the available experimental results are too few. In this connection, mention should be made of the illuminating discussion of the role of the experiments, as well as their interpretation and correlation with the mathematical theory of plasticity, given by Drucker (1949) and Prager (1948).

The present paper contains experimental results for ten tubular specimens possessing a rather severe initial anisotropy. The specimens, made of 24 S-T4 aluminium alloy, were subjected to combined action of tension and torsion with variable loading paths. The loading was such that tension alone was followed by torsion (accompanied with various amounts of tension) and permitted the determination of the initial shear modulus $G_{i}$ when twist began. Also included is a discussion of the experimental results in the light of the incremental-strain (flow) theories of plasticity.

\section{General Background}

For purposes of clarity, we discuss briefly plastic stress-strain relations of incremental-strain theories of plasticity and their consequences relevant to the experimental results given here.

On the assumption that the increment of plastic strains is linear in the increment of stresses, the plastic strain tensor, when expressed in terms of a plastic potential

\footnotetext{
- The results presented in this paper wrere obtained in the course of research sponsored by the Office of Ordnano: Rewearch under Contract DA-20-018-ORD-12099 with University of Michigan.
} 
$f$, reads as follows :

$$
\left.\begin{array}{rlrl}
\dot{\epsilon}_{i j}{ }^{\prime \prime} & =H \frac{\partial f}{\partial \sigma_{i j}} \frac{\partial f}{\partial \sigma_{k l}} \dot{\sigma}_{k l} & & \text { during loading i.e., } \frac{\partial f}{\partial \sigma_{k l}} \dot{\sigma}_{k l}>0 \\
& =0 & & \text { for unloading or neutral loading, i.e., } \frac{\partial f}{\partial \sigma_{k l}} \dot{\sigma}_{k l} \leqslant 0
\end{array}\right\}
$$

where repeated indices imply summation over all the values the index may take ; $H$ is a scalar function which may depend on the state of stress $\left(\sigma_{i j}\right)$, strain $\left(\epsilon_{i j}\right)$, as well as history of loading ; the dot denotes differentiation with respect to time, and prime and double primes refer to the elastic and plastic components of the strain, since it is tacitly assumed that the total strain tensor $\epsilon_{i j}=\epsilon_{i j}{ }^{\prime}+\epsilon_{i j}{ }^{\prime \prime}$.

The loading function $f$ in (1) may be such as to account for various degrees of initial and strain-hardening anisotropy. $\mathbf{A}$ few loading functions exhibiting this character have been suggested by Hill (1950) and Edleman and Dricker (1951). A simple example is

$$
f=C_{i j k l} \sigma_{i j} \sigma_{k l}
$$

which is quadratic in $\sigma_{i j}$ and accounts for small initial anisotropy. In (2), $C_{i j k t}$ is a fourth-order symmetric tensor, i.e., $C_{i j k l}=C_{k l i j}, C_{i j k l}=C_{j i k l}, C_{i j k l}=C_{i j k k}$. From the assumption of incompressibility of plastic strains, $\frac{\partial f}{\partial \sigma_{p p}}=C_{p p k l} \sigma_{k l}=0$ for all $\sigma_{k l}$; hence $C_{p p k l}=0$ for all $k, l$.

For isotropic theories of plasticity, $f$ may be a function of both $\sigma_{i j}$ and $\epsilon_{i j}$. When $f$ is a function of $\sigma_{i j}$ alone, the stress-strain relations (1) may be referred to as isotropic stress theories. In particular, it is easily seen that the simple incremental-strain theory

$$
\dot{\epsilon}_{i j}^{\prime \prime}=H\left(J_{2}\right) s_{i j} \dot{J}_{2}
$$

is a special case of (1), when $H$ is assumed to depend only on $J_{2}$ and $f=J_{2}$, i.e.,

where

$$
J_{2}=\frac{1}{2} s_{i j} s_{i j}
$$

$$
s_{i j}=\sigma_{i j}-s \delta_{i j} ; \quad s=\frac{1}{3} \sigma_{i i} .
$$

and $\delta_{i j}$ is the Kronecker delta.

In the experimental results which are to be described, the determination of the initial shear modulus $G_{i}$ when twist began is included (the loading was such that tension alone was followed by torsion). For this reason, it is desirable to examine the predictions for $G_{i}$ by various theories of plasticity, appropriate for such loading paths.

All isotropic incremental-strain theories of plasticity imply that (Pracer 1948 ; Peters, Dow and Batdorf 1949)

$$
G_{i}=G_{0} \text { for both loading and unloading }
$$

for all ratios of the increments of axial stress to shear stress, $d \sigma_{\mathbf{2 3}} / d \sigma_{23}$ or simply $d g / d \tau$. Similarly, all isotropic total strain (deformation) theories predict that (Petens, Dow and Batdorf 1949) 


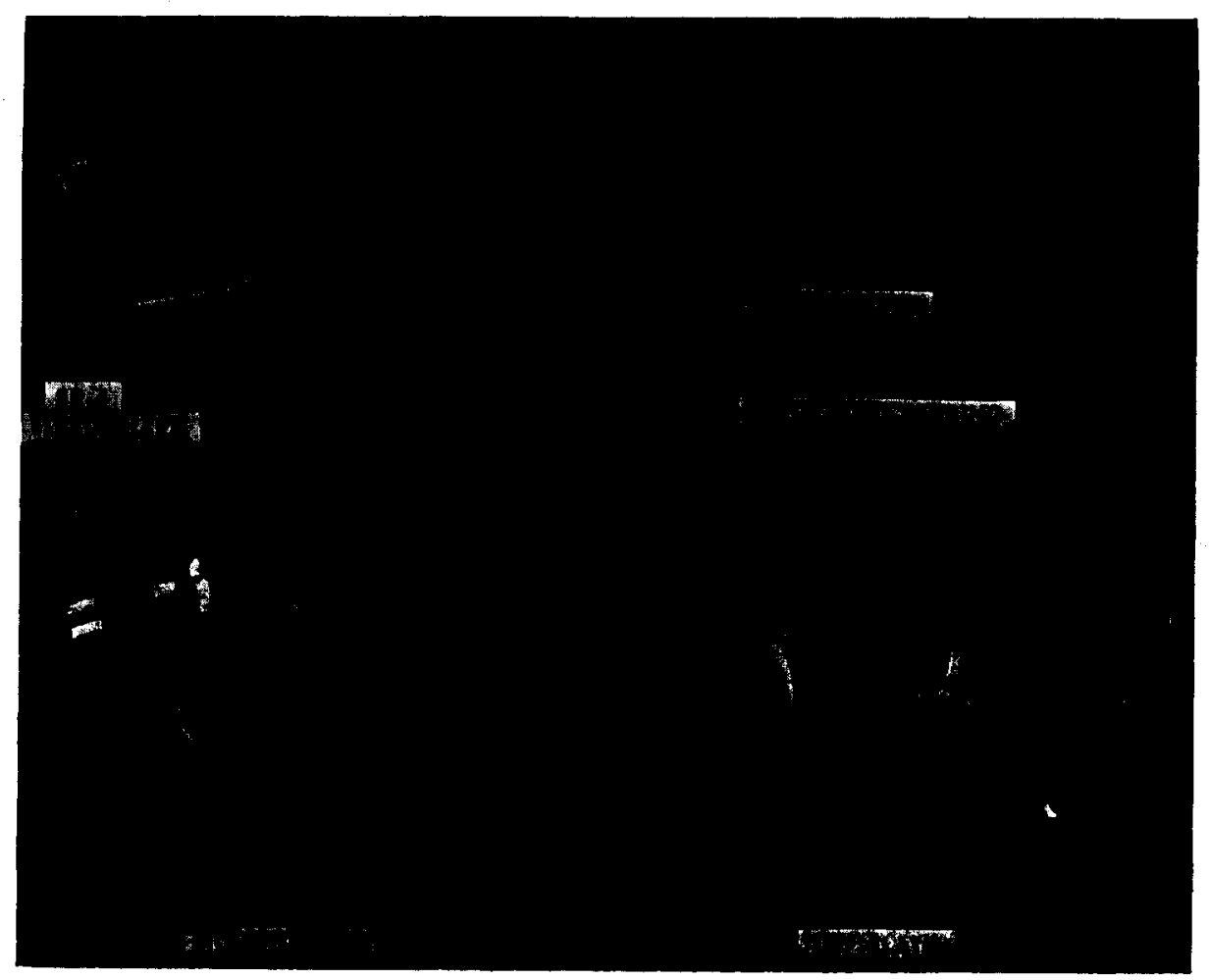

Fig. 1.

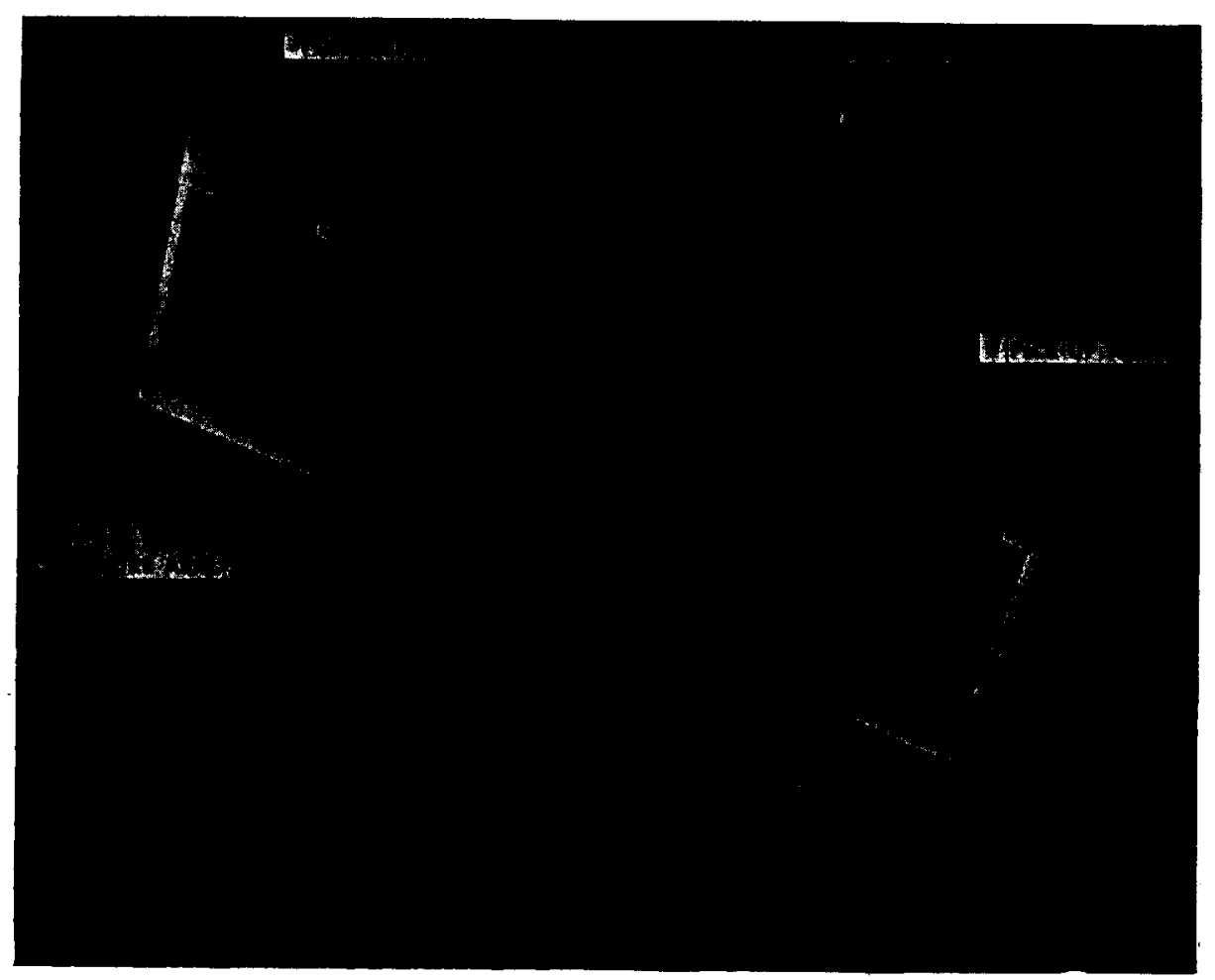

Fig. 2. 


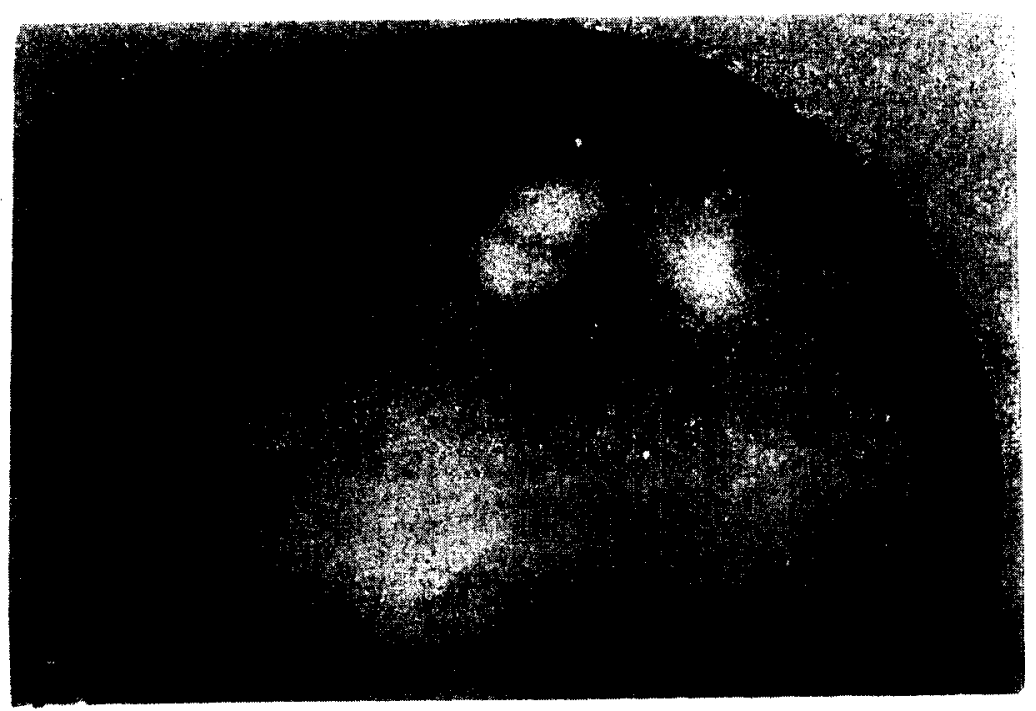

Fig. 4. 
An experimental study of biaxial stress-strain relations in plasticity

$$
\begin{aligned}
G_{i} & =\frac{G_{0}}{1+3 G_{0}\left(1 / E_{*}-1 / E_{0}\right)} & & \text { for loading } \\
& =G_{0} & & \text { for unloading }
\end{aligned}
$$

where $E_{a}$ is the secant modulus with reference to the initiation of twist, and $E_{0}$ and $G_{0}$ are the elastic moduli in tension and shear.

If, however, in equation (1) $f$ is an anisotropic loading function, then during loading $G_{i}$ will in general be less than $G_{0}$. To demonstrate this point, let $f$ be of the form given by (2); then it follows that

$$
\begin{aligned}
G_{i} & =\left[\frac{d \sigma_{28}}{2\left(d \epsilon_{28}{ }^{\prime}+d \epsilon_{23}{ }^{\prime \prime}\right)}\right]_{\sigma_{28}=0} \quad \text { during loading } \\
& =1+2 \overline{G_{0} H C_{2838}} \sigma_{88}{ }^{2}\left[\overline{2 C_{2838}}+C_{8898} d \sigma_{88} / d \sigma_{28}\right]
\end{aligned}
$$

\section{Equipment and Specimens}

The accuracy requirements and attendant difficulties peculiar to experimental investigations in plasticity, as opposed to the usual testing procedures in materials testing, have been emphasized recently by Drucker and STockTon (1952). In this section, we outline briefiy the experimental set-up developed to include features necessary to meet these rather special requirements.

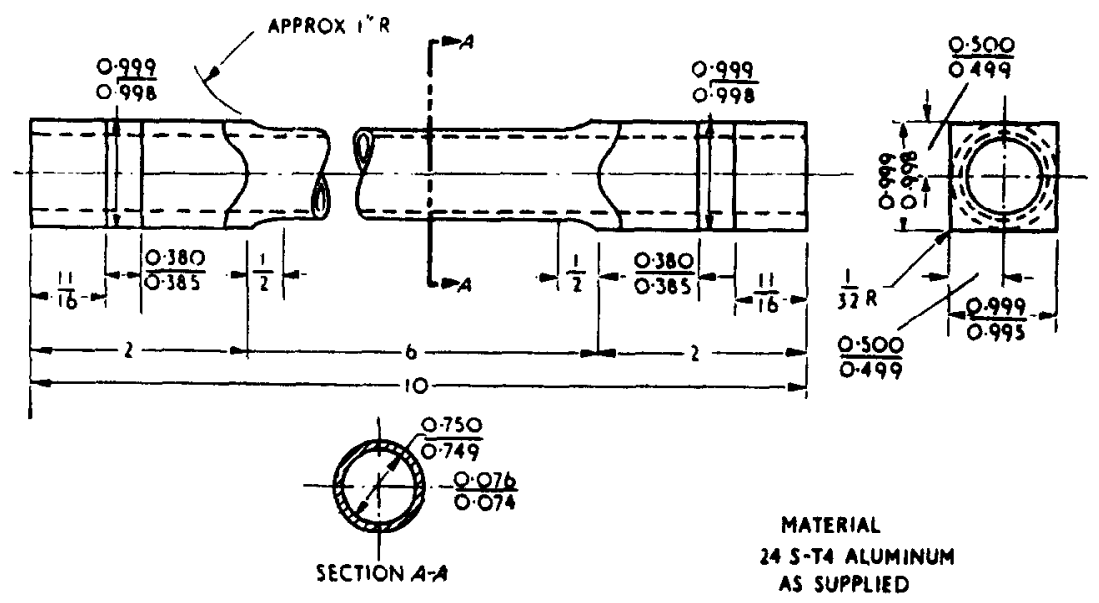

Fig. 3. Drawir.g of thin-walled specimen.

The testing machine used in this study to apply the combined tension and torsion loads is powered by electric motors which drive the loading bar through variable speed transmiasions. The load ranges of 10,000 lbs. in tension and 10,000 inch-lbs. in torsion, together with the wide continuous range of strain rates available, make the machine particularly suited to this type of investigation. The magnitudes of the loads are indicated on dynamometers having both a dial for direct visual readings and a resistance strain gauge bridge for electrical recording.

The extensometer for the indication of the deformations of the tubular specimens was developed under the following considerations : it should preferably have linear characteristics; the deformation measurements should be independent; backlash and lag must be negligible ; a wide range of plastic deformations must be covered with a precision comparable to that required for elastic strains ; and finally, the output of the extensometer should be such that electrical recording 
would be possible. Fig. $I$ and 2 show the extensometer as used in these tests. The instrument has a nominal gauge length of $\mathbf{2 \cdot 8 4}$ inches and consists of two aluminium disc fastened to the specimen with spring loaded screws. The screw contact force is roughly $5 \mathrm{lbs}$. and the weight of the extensometer is approximately $2 \mathrm{l}$ lbs. The relative angle of twist of the two dises is measured by a resistance slide wire wound on the periphery of the upper plate and two contacts fastened to the lower disc but allowed free axial motion through a thin spring brass cantilever system. The axial deformation is indicated by an extension unit made up of a steel ring attached to the bottom disc by four thin bronze flexure strips, each having two SR-4 strain gauges attached at a reduced section. As the extensometer is placed on the specimen, this extension unit is slightly compressed and the top disc rides on the steel ring through three small instrument bearings. Unfortunately, a means for indicating the circumferential deformations was not successfully developed, these attempts being principally thwarted by the difficulty of obtaining a reproducible calibration and the fact that the tubular specimens tended to distort to non-circular cross-sections.

The dimensions of the specimens are indicated in the drawing reproduced in Fig. 3. Tolerances were held to 0.001 inch in both eccentricity of bore and wall-thickness taper. The specimens were taken from the centre of two-inch thick rolled plates of 24 S-T4 aluminium alloy having a grain size of roughly 500 grains per inch, and considerable intial anisotropy was present, as
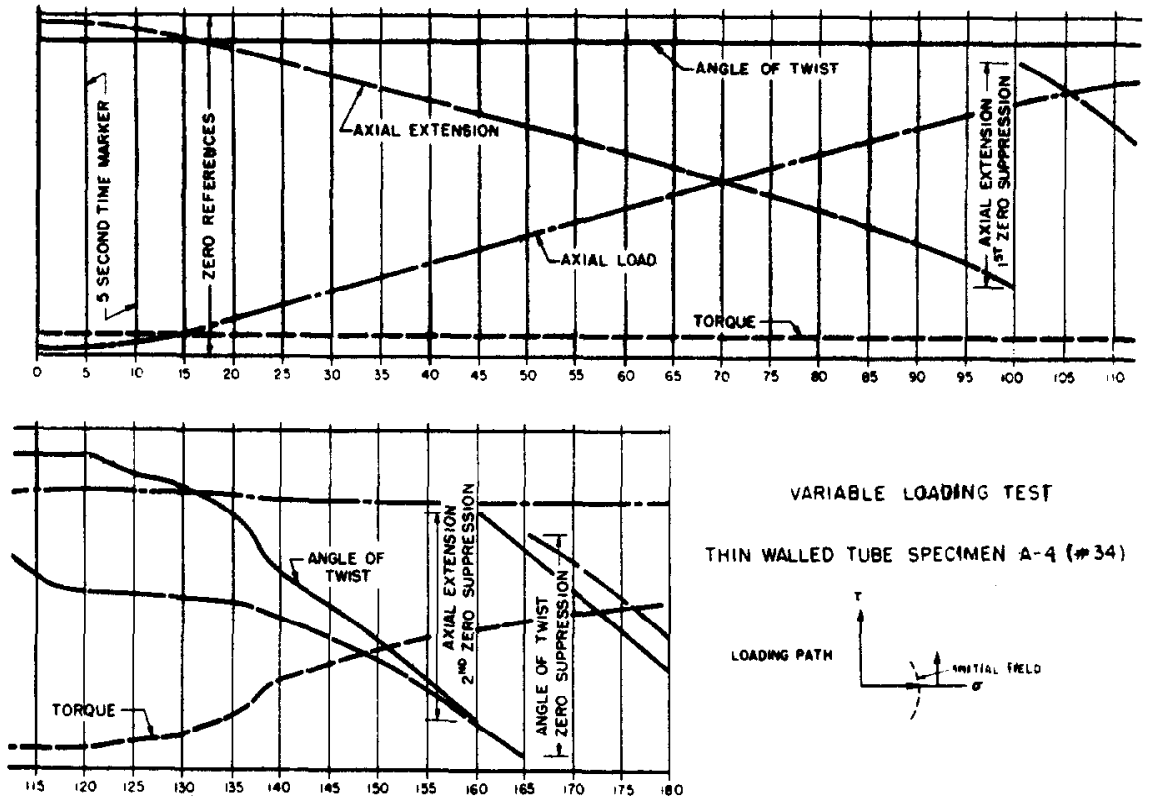

VARIAGLE LOADING TEST

THIN WALLEO TUBE SPECIMEN $:-4(-34)$

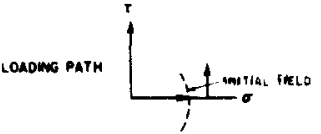

Fig. 5.

indicated by Fig. 4 which shows one half of a cross-section. The design requirements on wall thickness were dictated by (i) elastic and plastic buckling in torsion (Moore 1943) ; (ii) dimensions of the extensometer ; and (iii) the available loading range of the tension-torsion machine. The influence of the effects introduced by the fllets at the ends of the specimens was investigated by placing several strain gauges along the length of a tube. The variation of strain reading in tension over the region occupied by the extensometer gauge length was found to be only about $1 \%$.

The ancuracy of the load indications is limited to about $\pm 2 \%$ since the calibration was made against a laboratory testing machine, although relative values of load are probably better. The slight interaction of the extension and twist measurements reduced the precision at the corresponding strain readings to at most \pm 50 micro-inches, although individually, the calibration and resolution were to about \pm 10 micro-inches or better. 
Continuous recording of both deformation and load was performed on photographic Alm, using mirror galvanometers in an oscillograph (HATHAwAy model S14-A). A facsimile of one ouch f 'm for a variable loading path test is shown in Fig. 5. All recording circuits were of the Wheatstone bridge type, thus affording inherent temperature stability and ease of calibration by chopping fixed resistors across the flxed bridge arms.

\section{Experimental Results}

The variable loading path tests, performed on ten thin-walled tubular specimens, consists of tension alone followed by torsion with varying amounts of accompanying tension. The test specimens and their data have been arranged in four groups (designated as $A, B, C, D$ ) according to the value of the ratio of additional tension to torsion at the initiation of the torque. This grouping is indicated in Fig. 6, where, in conformity with engineering notation, $\sigma_{z}$ and $\tau_{\theta_{z}}$ (or simply $\sigma$ and $\tau$ ) denote the axial and shearing stresses in the tubular specimen. Also shown in Fig. 6 is the approximate value of the initial slope $d \sigma / d \tau$ for each group.

The test data obtained are presented in the form of curves in Figs. 7-16. For each group of specimens, three sets of curves are plotted: axial stress vs. axial strain, showing where twist began ; elastic and initial shear moduli, including two elastic runs before and after each experiment (the first run was performed on the virgin tube in each case); and plastic strains occurring after initiation of twist. In each group, the secant modulus was computed to be approximately $7 \times 10^{6}$ psi.

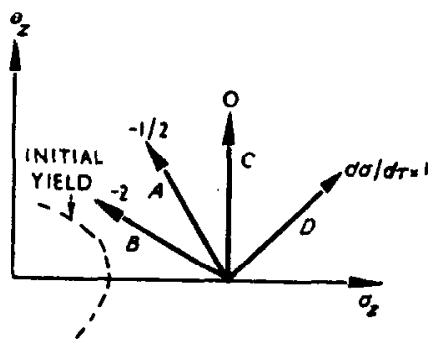

Fig. 6.

The uniformity of the dimensions of the specimens used was very good. As inidicated in Fig. 8, all tubes had an 0.075 inch nominal wall thickness and 0.75 inch inside diameter, with the exception of $D-1$ and $D-2$ tubes which had the same inside diameter but a wall thickness of 0.055 inch.

The curves of Figs. 7-16 also illustrate several limitations of the experimental set-up. First, a glance at the loading paths as plotted indicates the difficulty encountered in maintaining a linear stress path with a machine that is essentially a straining machine. Second, a slight tendency for the shear stress to lag occasionally in the initial portions of both elastic and plastic shear stress - shear strain curves (e.g., Fig. 12b) is a reflection of a small residual stickiness of the loading ram. Finally, the data for tube $B-1$ (Fig. 12) affords an excellent evaluation of the small amount of interaction that remains between the axial-extension and angle-of-twist measurements. The deviations of the plastic strain from the zero axis (Fig. 12c) occurring before the deformation has become plastic are probably due to this interaction.

\section{Discussion of Results}

With reference to Figs. 7-16, it is seen that the repeatability of the experimental results is good and that for Group $A$ specimens this extends over five tubes. In this connexion it should be mentioned that the agreement in the values of elastic 


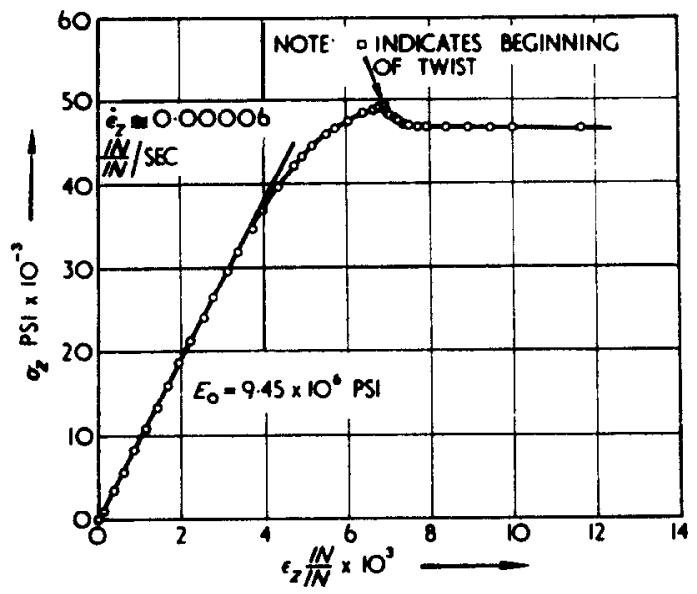

Fig 7a. Axial stresa vs. axial strain tube A-1 (No. 27).
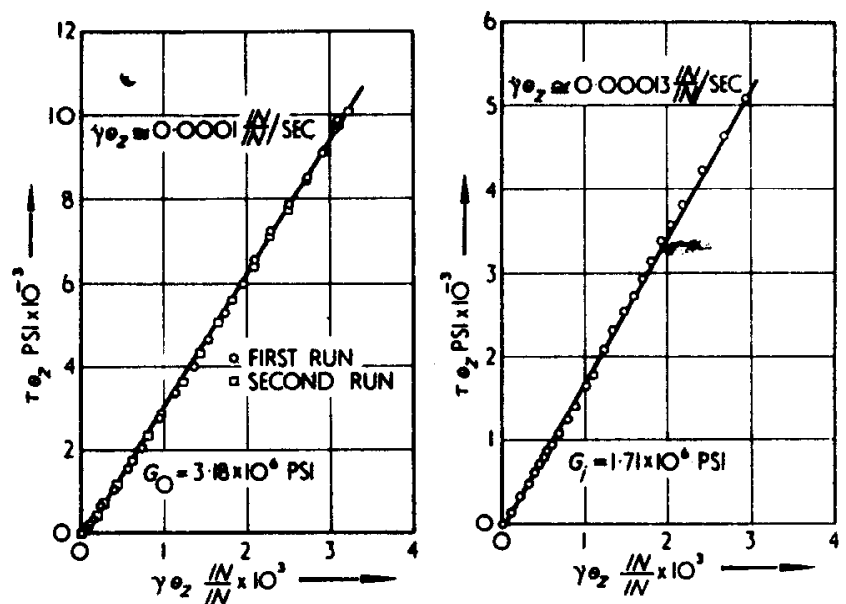

Fig. 7b. Elastic and initial shear moduli tube A-1 (No. 27).

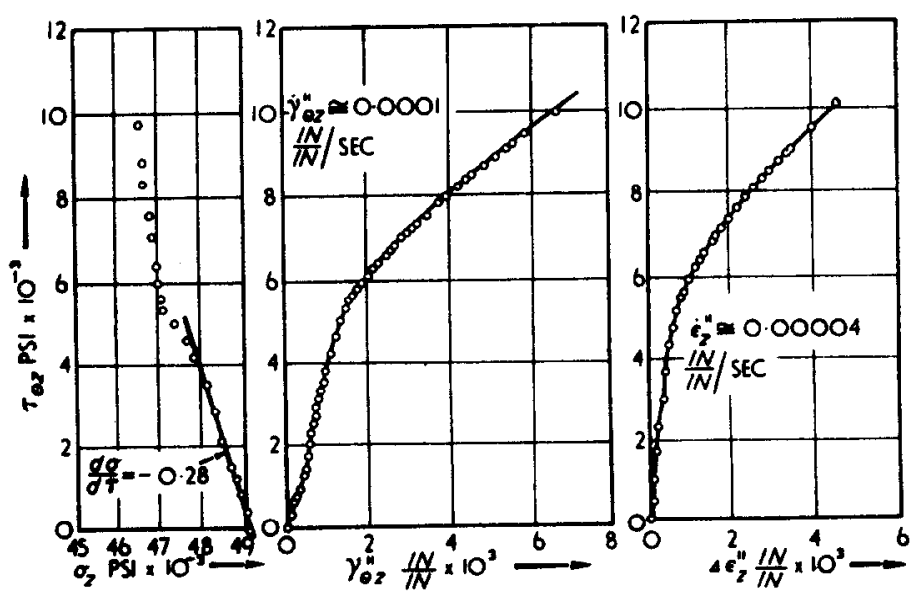

Fig 7c. Plastic strains and loading path tube A-1 (No. 27). 


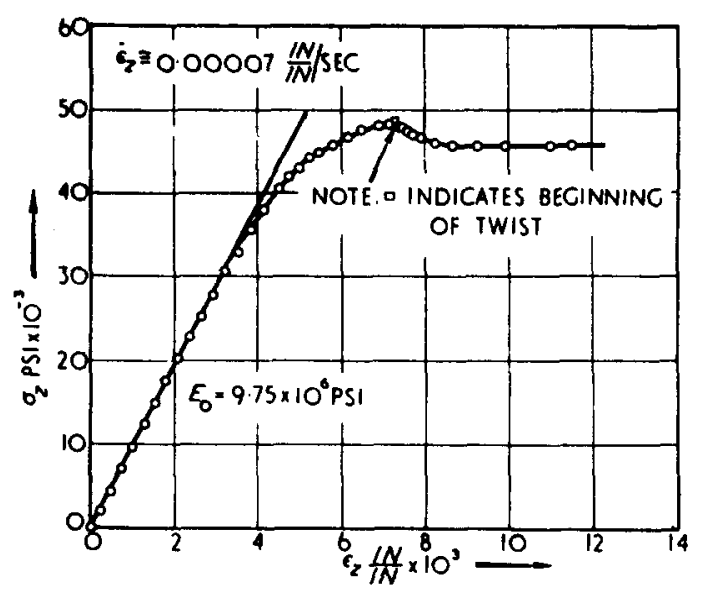

Fig. 8a. Axial stress vs. axial strain tube A.2 (No. 29).
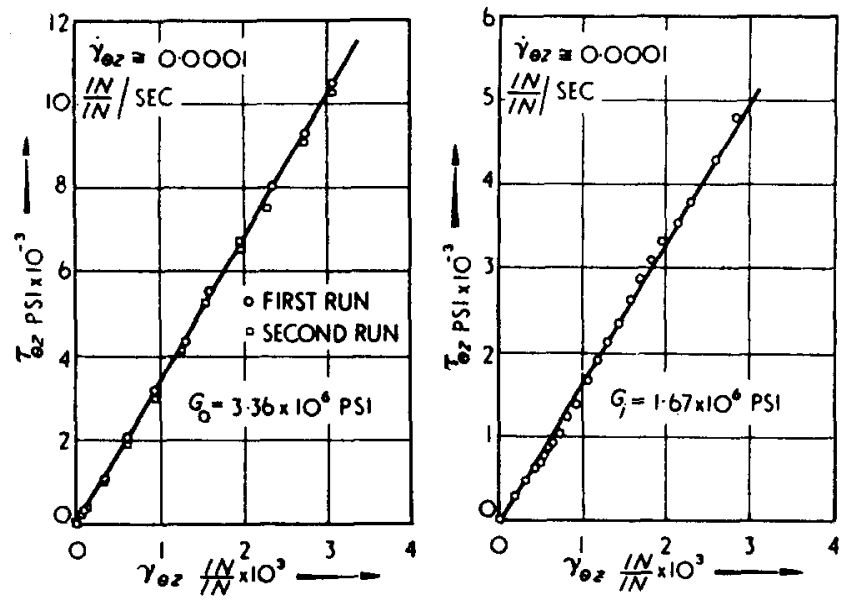

Fig. 8b. Elastic and initial shear moduli tube A-2 (No 29).
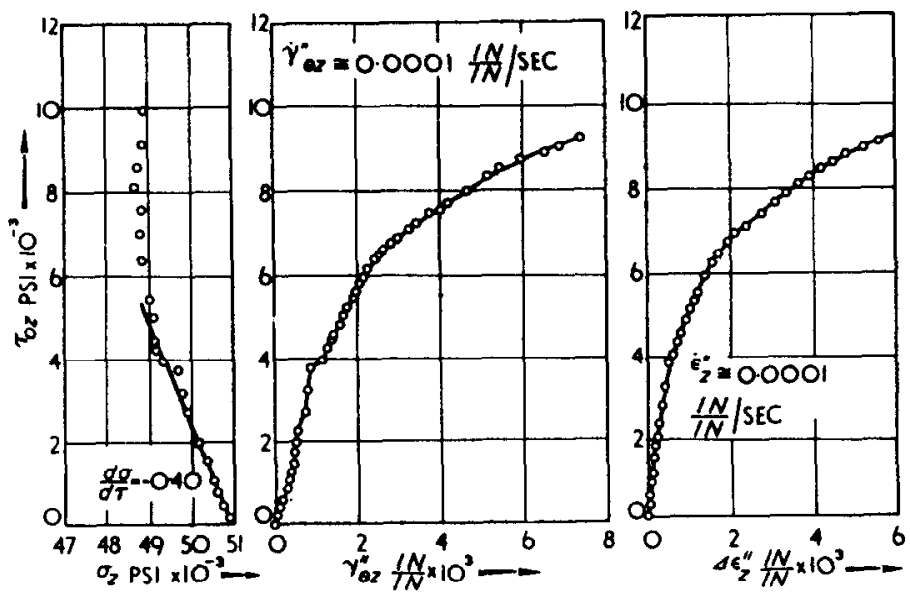

Fig. 8c. Plastic strains and loading path tube A.2 (No 20). 


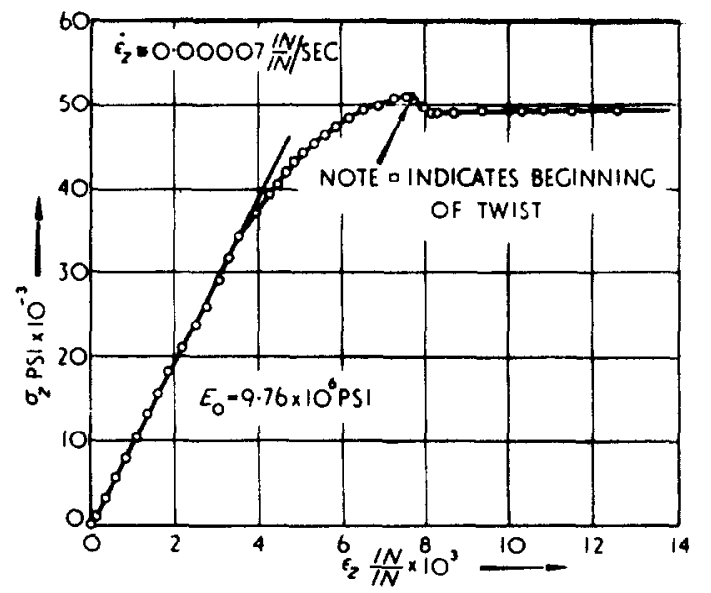

Fig. 98. Axial stress vs, axial strain tube A-3 (No. 31).
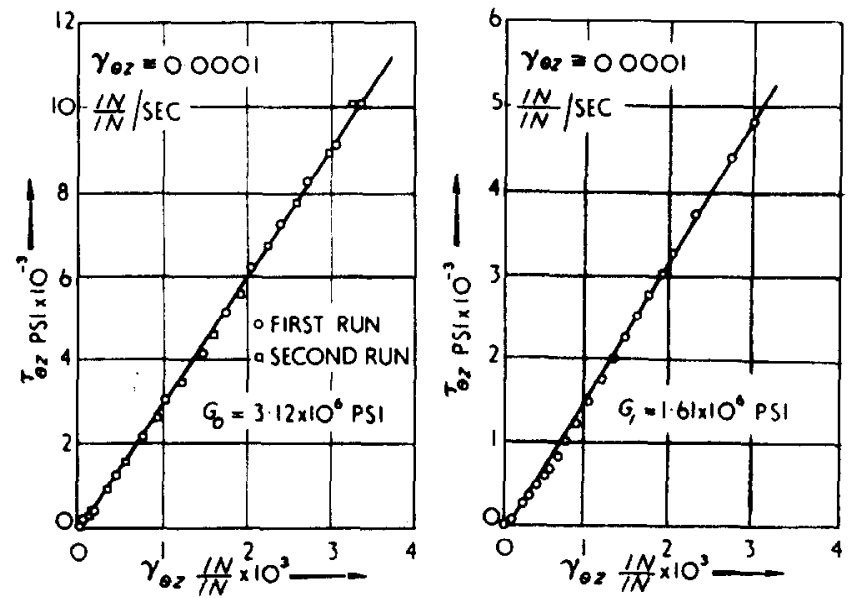

Fig. 9b. Elastic and initial shear moduli tube A-3 (No. 31).
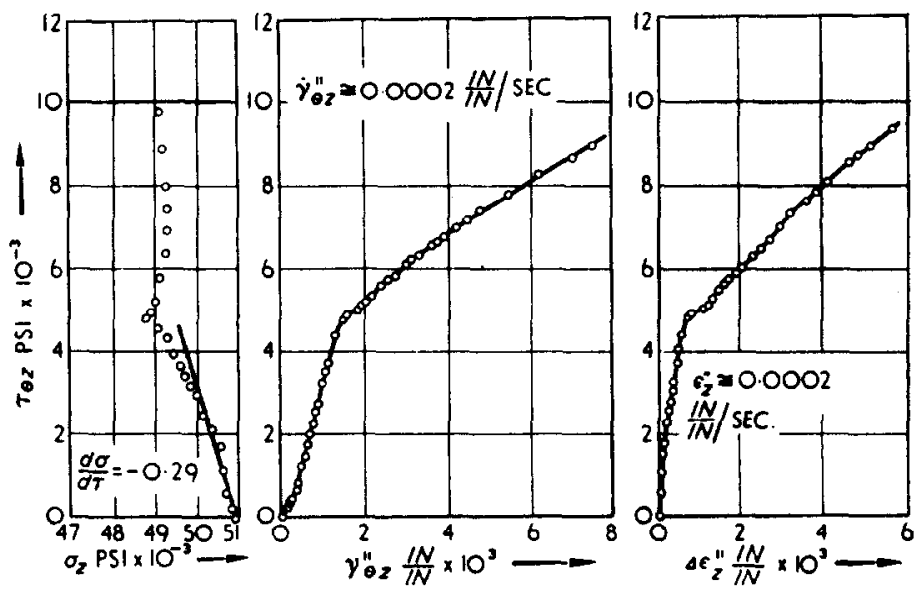

Fig. 9c. Plastic struins and loading path tube A-3 (No. 31). 


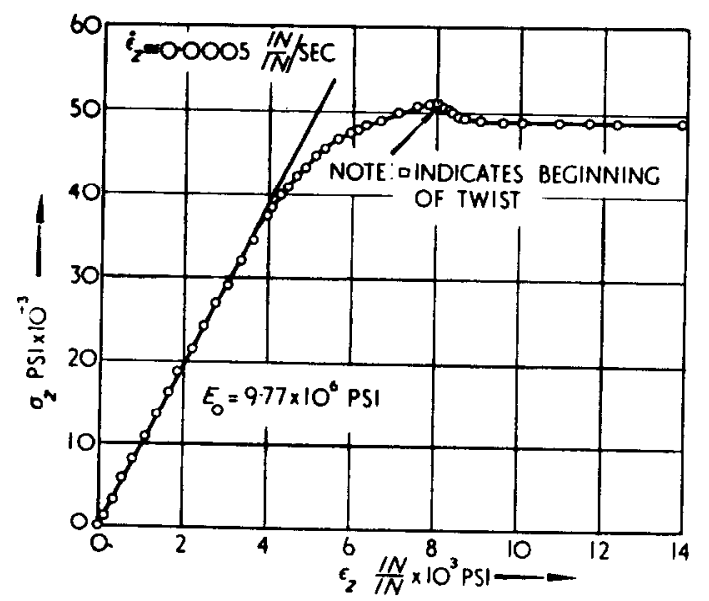

Fig. 10a. Axial stress vs. axial strain tube A-4 (No. 34).
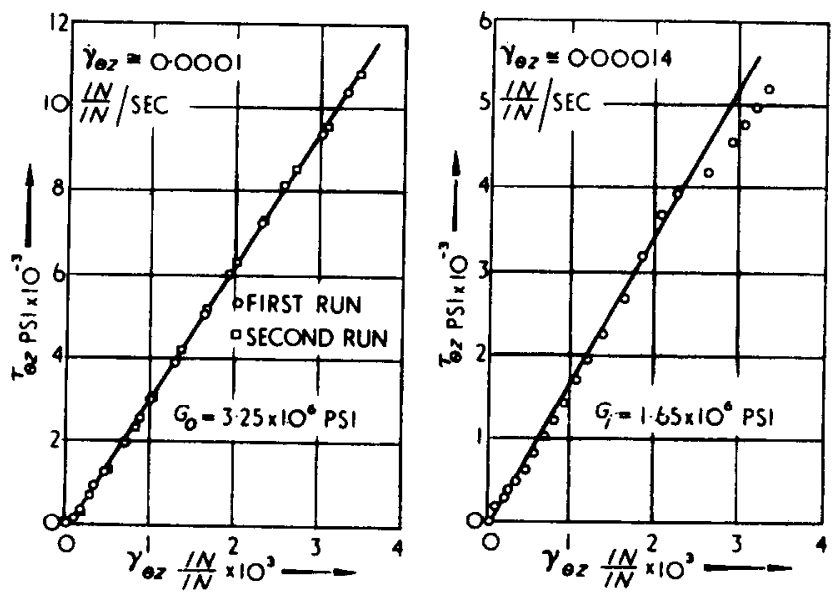

Fig. 10b. Elastic and initial shear moduli tube A-4 (No. 34).
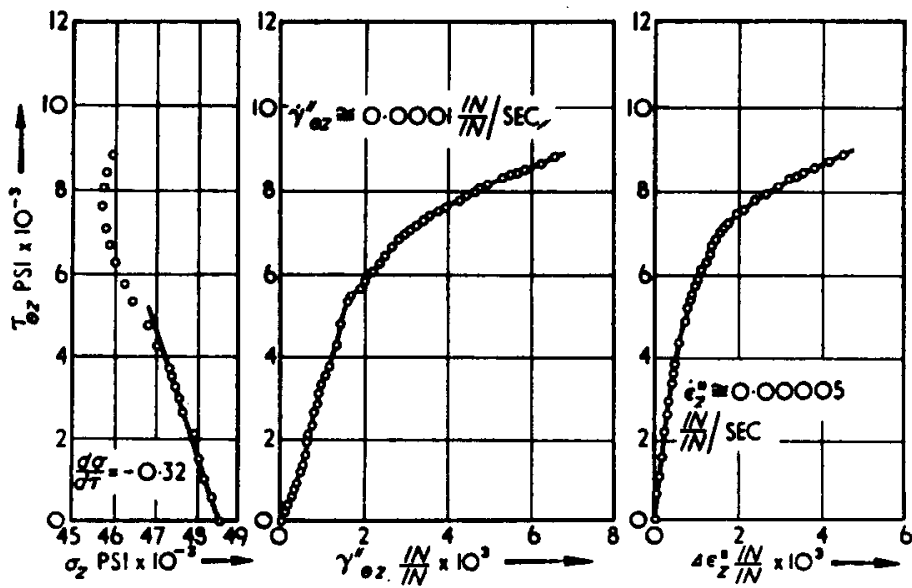

Fig. 10c. Plastic strains and loading path tube A-4 (No. 34). 


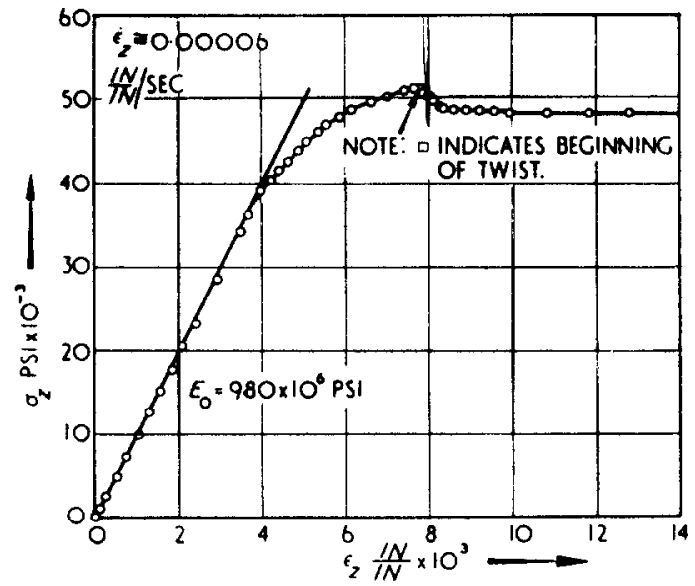

Fig. 11a. Axial stre ss vs. axial strain tube A-5 (No. 35).
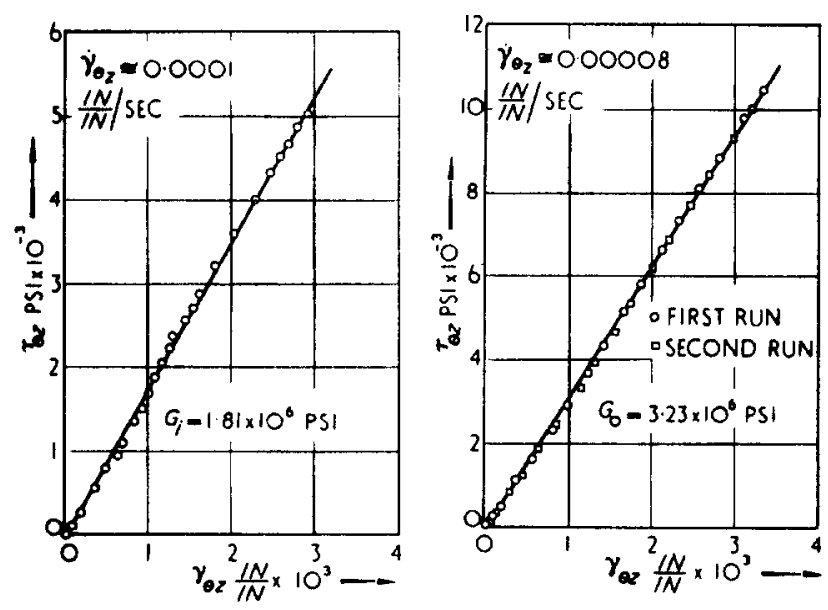

Fig. 11b. Elastic and initial shear moduli tube $A-5$ (No. 35).
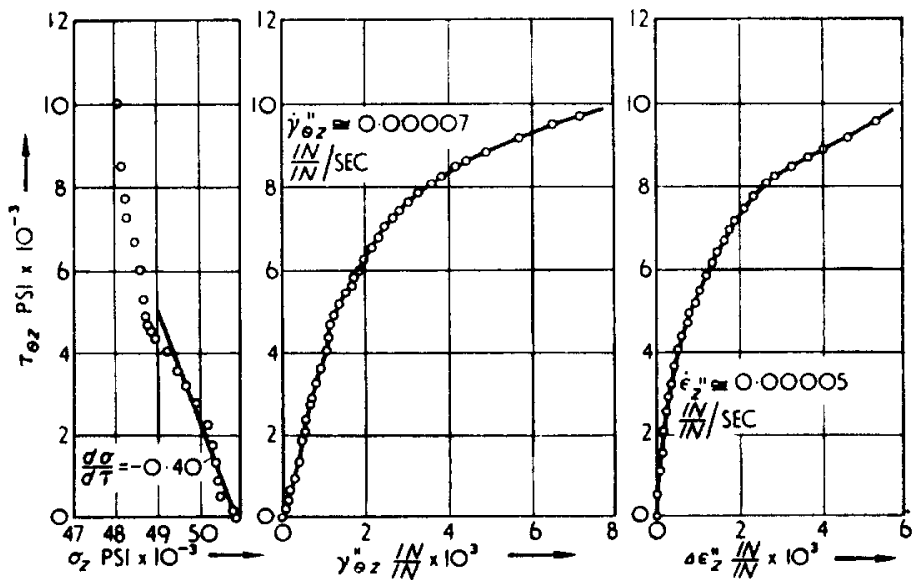

Fig. 11c. Plestic strains und loading path tube A-5 (No. 35). 


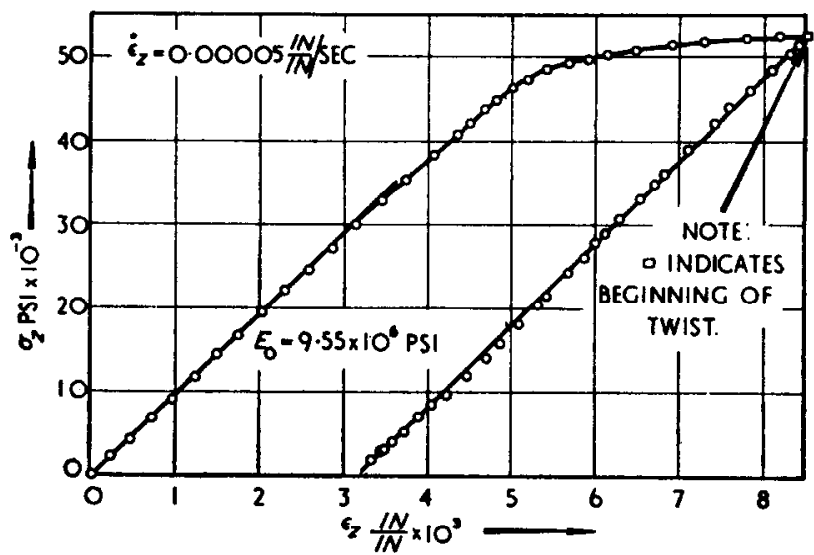

Fig. 12a. Axial stress vs. axial strain tube B-1 (No. 51).
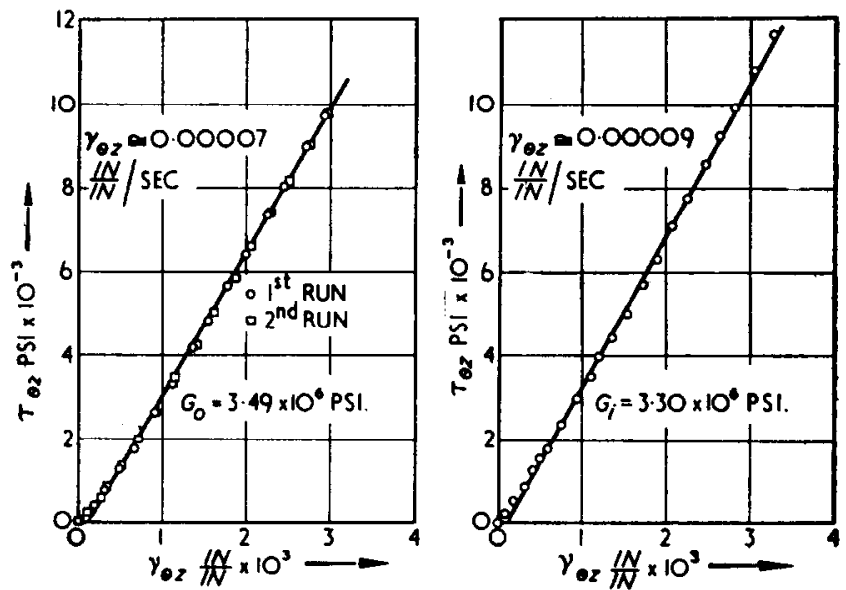

Fig. 12b. Elastic and initial shear moduli tube B-1 (No. 51).

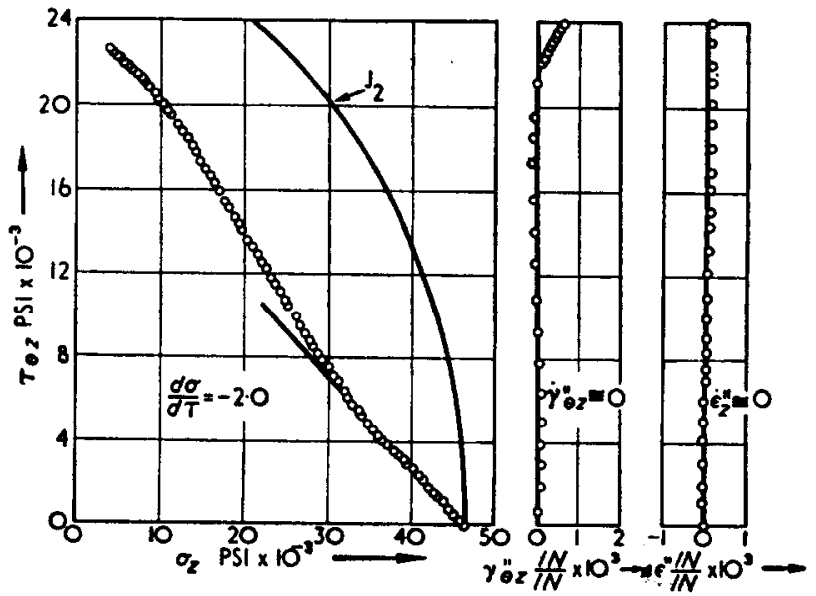

Fig. 12c. Plastic strains and loading path tube B-1 (No. 51). 


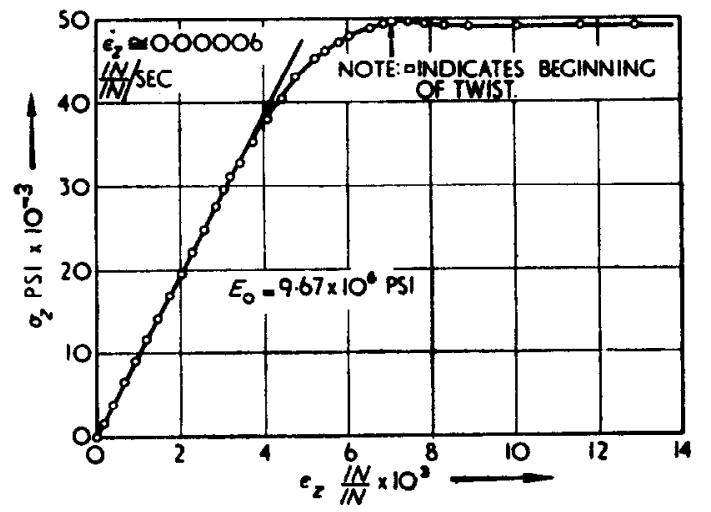

Fig. 18a. Axial stress vs. axial strain tube C-1 (No. 86).
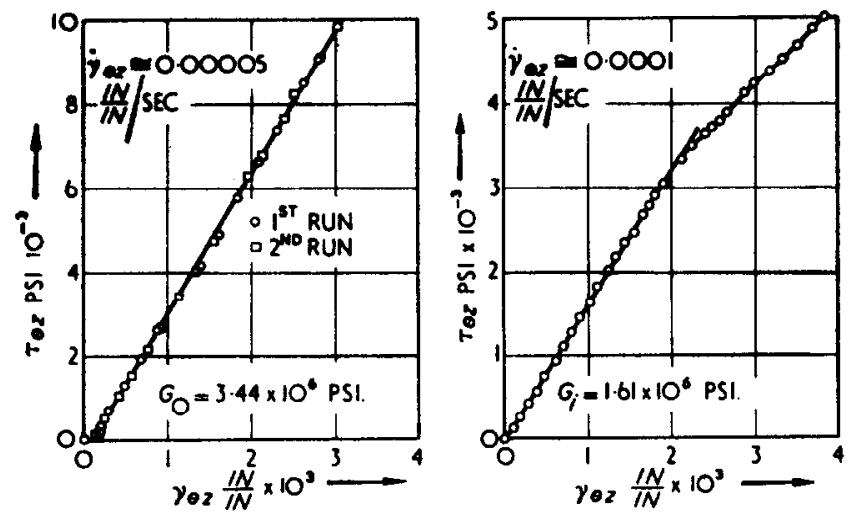

Flg. 18b. Elastic and initial shear moduli tube C-1 (No. 86).
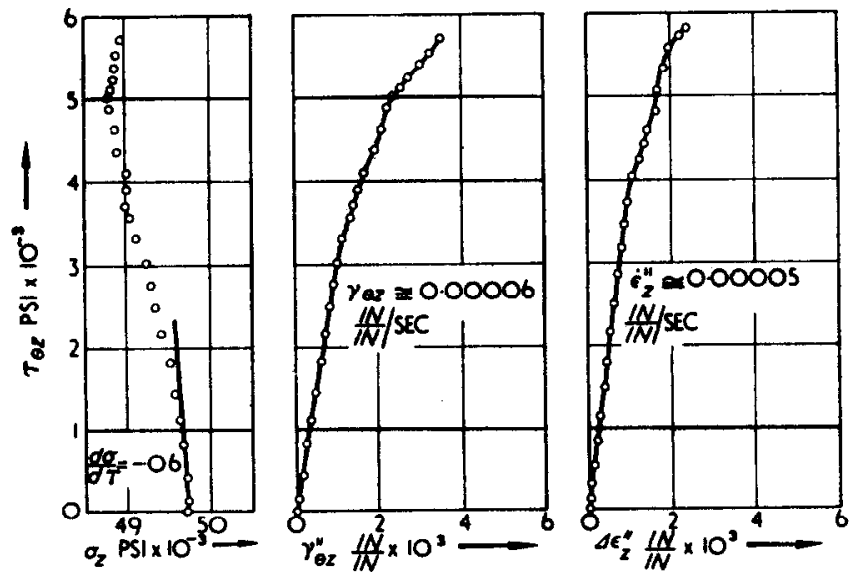

Fig. 13c. Plastic strains and loading path tube C-1 (No. 36). 


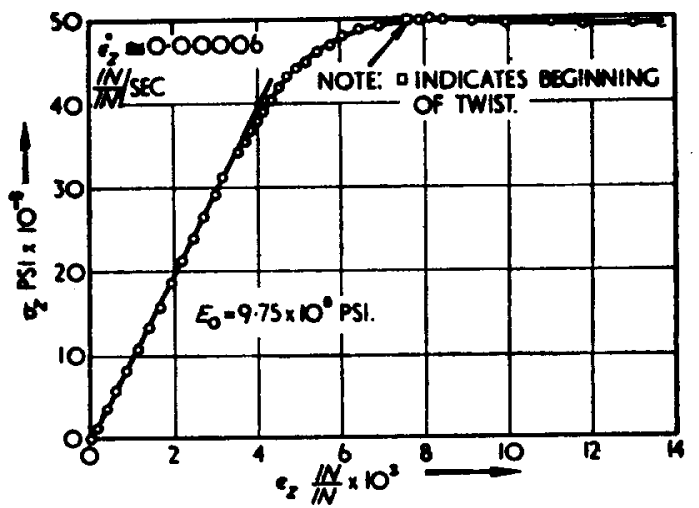

Fig, 14a. Axial stress vs. axial strain tube C-2 (No. 50).
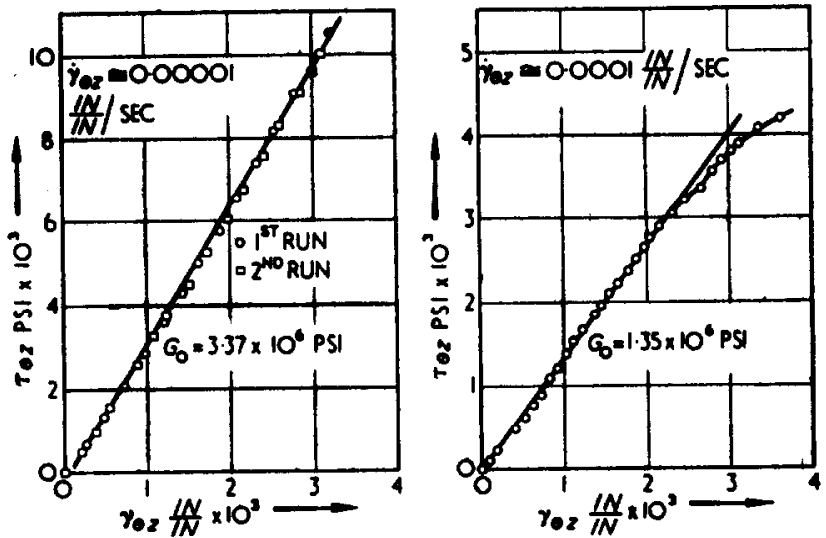

Fig. 14b. Flastic and tnitial shear modull tube C-2 (No. 50).
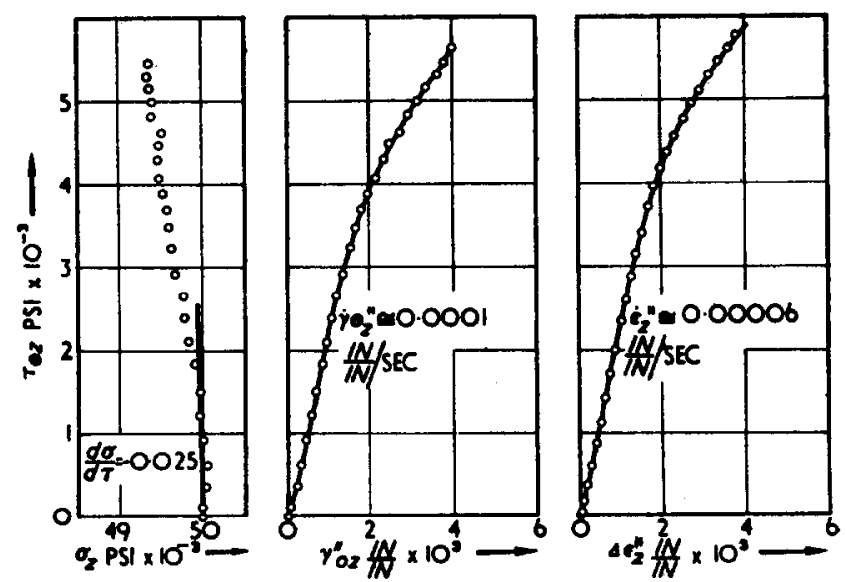

Fig. 14c. Plastic strains and loading path tube C-2 (No. 50). 


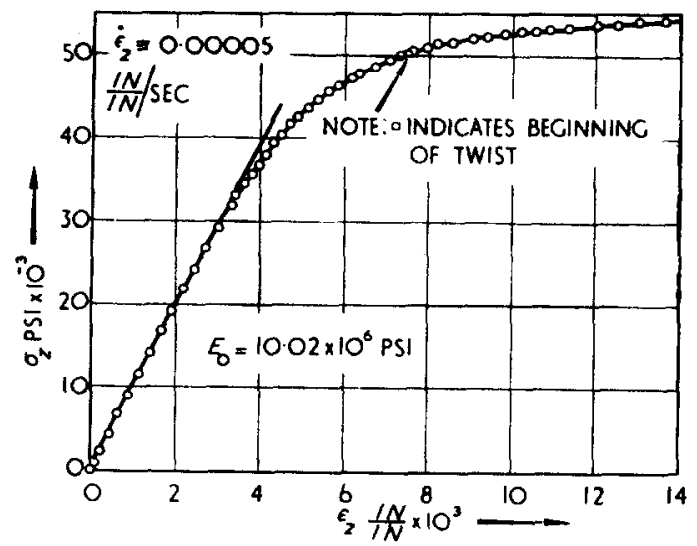

Fiy. 15a. Axial stress vs. axial strain tube D-1 (No. 55).
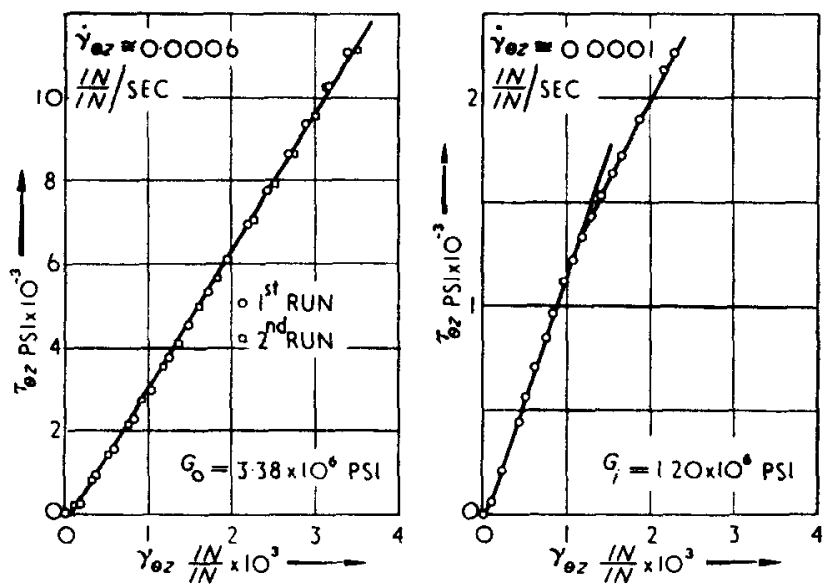

Fig. 151). Elastic and initial shear moduli tube D-1 (No. 55).
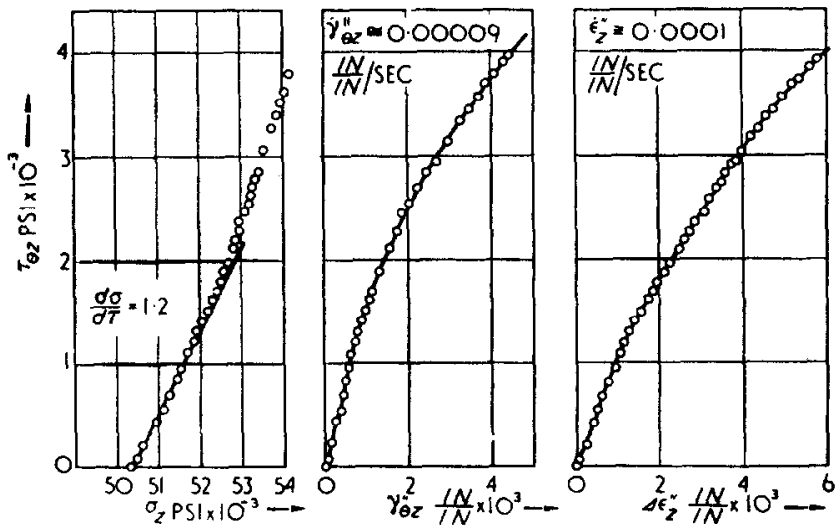

Fig. 15r. Plastic strains and loading path tube D-1 (No. 55). 


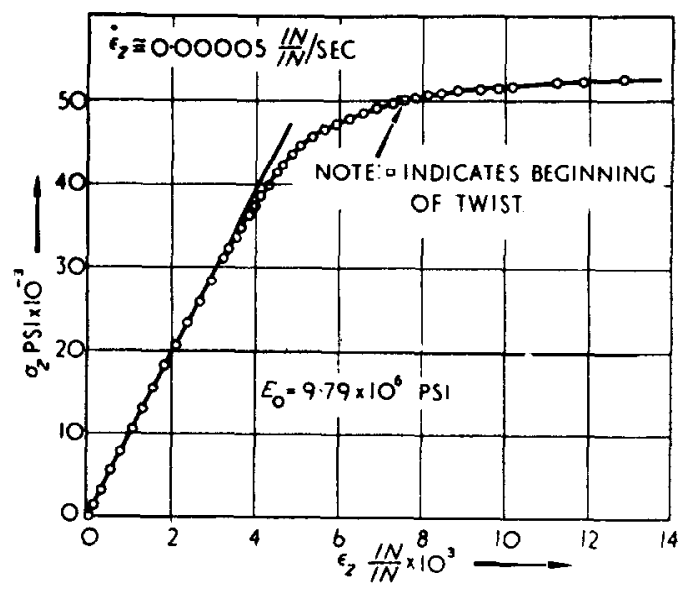

Fig. 16a. Axial stress vs. axial strain tube D-2 (No. 56).
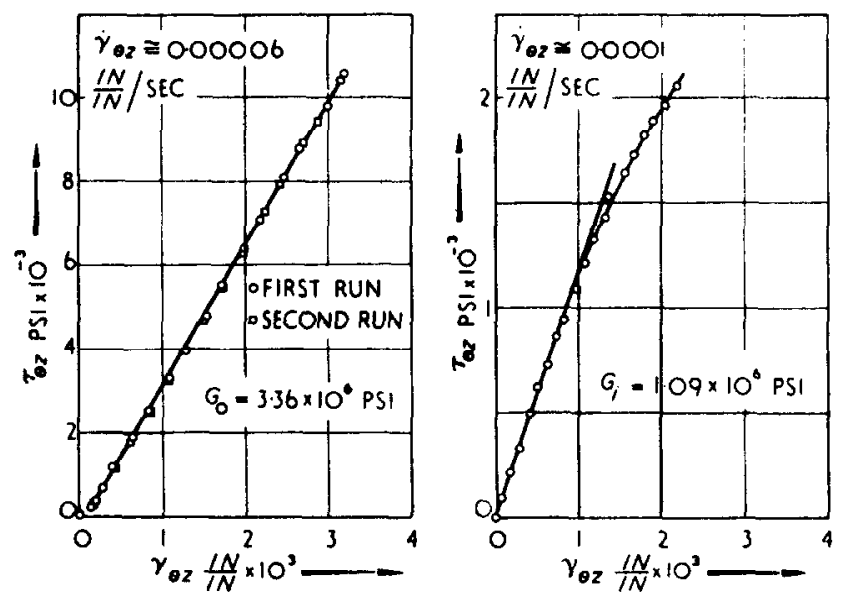

Fig. 16b. Elastic and initial shear moduli tube 1 .2 (No. 56).
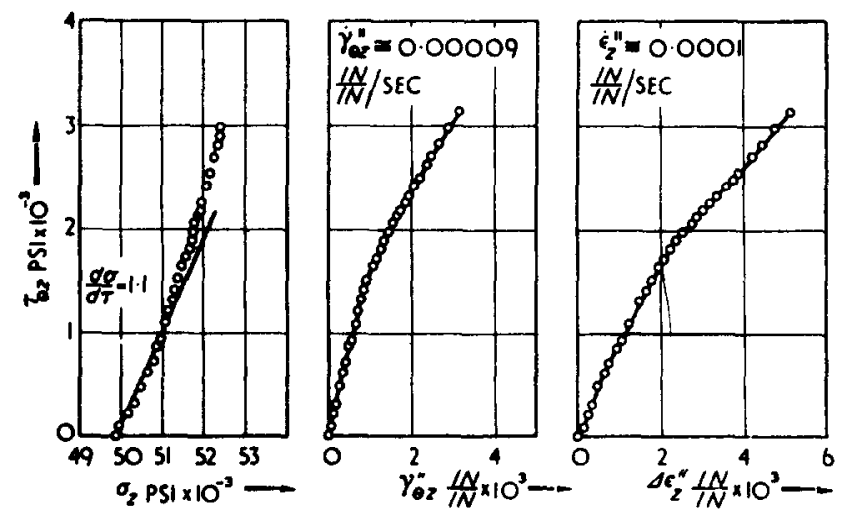

Fig. 16c. Plastic strains and loading path tube D-2 (No. 56). 
constants (Figs. 7-16) is remarkable in view of the presence of rather severe initial anisotropy in the tubular specimens.

For Group $\boldsymbol{A}$ the shear modulus $G_{i}$ is less than the elastic shear modulus $\boldsymbol{G}_{0}$ (Figs. 7-11) by about a factor of 2. Apparently such a phenomenon has not been reported by previous investigators. This effect may be attributed in the main to the prescence of both initial and strain-hardening anisotropy and/or the nonexistence of smooth yield loci.

For purposes of discussion, let us assume the existence of smooth yield loci and accept the validity of the linearity of the plastic strains in the increment of stresses (Drccker and Stockton 1952; Stocktos 1953). Consider the subsequent yield surface $f_{2}$ for an initially anisotropic strain-hardening material, as shown
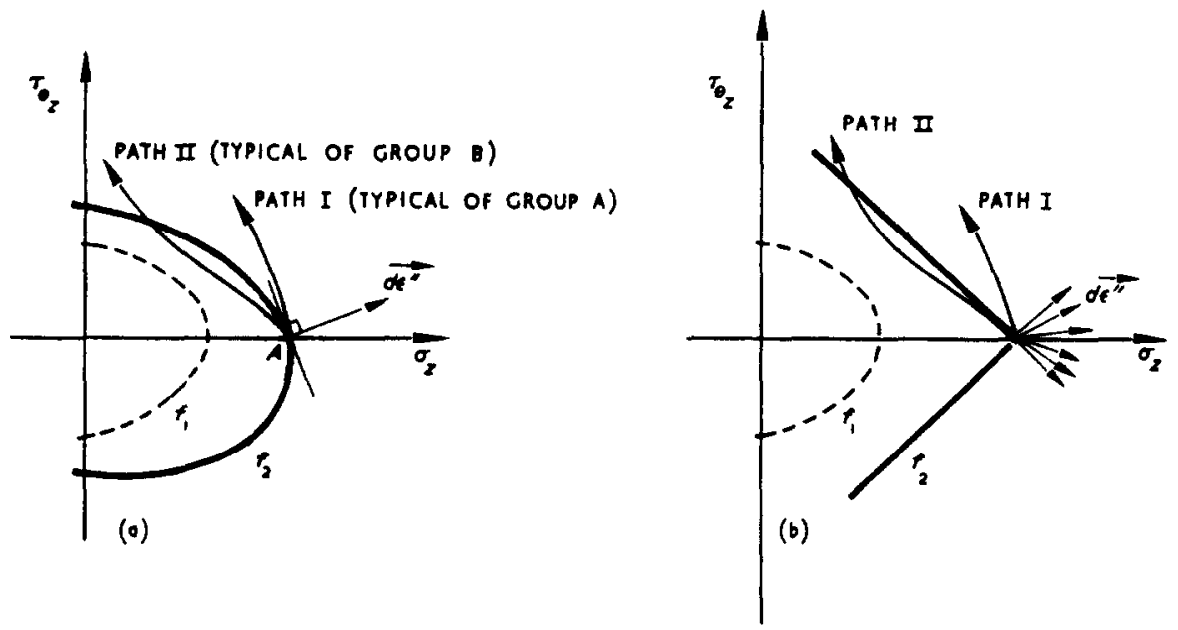

Fig. 17.

in Fig. 17a. This hypothetical loading surface is drawn so that the tangent at $A$ (when travelling in a counterclockwise direction) makes an obtuse angle with the axis $\sigma_{z^{*}}$ Also shown in Fig. 17a are typical loading paths for Groups $A$ and $B$ specimens.

As pointed out by Bishop and Hir.. (1951) and Dr' ('KFk (1951), when the loading surface has neither corners nor pointed vertices, the increment of the plastic strain vector is normal to the loading surface. Hence, the plastic strain vector d $\epsilon^{\prime \prime}$ at $A$ in Fig. $17 a$ is along the external normal to $f_{2}$ and has both axial and shearing components. Clearly, then, $G_{i}$ at $A$ (beginning of twist) should not be equal to $G_{0}$. Furthermore, along the loading path $I$, additional plastic deformation should be produced. Thus, if the yield locus $\int_{2}$ is smooth, then, according to the results for Group $A$ specimens, it must be oblique to the $\sigma_{z}$-axis as shown in Fig. 17a. This, however, implies that (i) experimental results for a loading path, such as $I$ in Fig. 17a, and its image about the $\sigma_{z}$-axis are not the same ; and (ii) under a pure tensile load, the tubes would twist as well as extend, which definitely did not occur. In view of these faulty characters of the smooth locus $f_{2}$ in Fig. 17a. one may alternatively reach the conclusion that the existence of a corner at $A$ on a yield locus symmetrically situated about the $\sigma_{z}$-axis is plausible (Fig. 17b). In 
Fig. 17b, it should be noted that the direction of the plastic strain vector de" is not uniquely defined and is restricted only to the directions included between the normals to the adjacent surfaces at $A$.

With reference to Fig. $17 \mathrm{~b}$, if the loading path is as in Group $B$, then $G_{i}$ would be expected to have the elastic value $G_{0}$, considering that unloading has definitely occurred. That this is indeed the case can be seen from Fig. 12 where $G_{i} \simeq G_{0}$. The small amount of deviation in these values is not unreasonable in view of the presence of initial anisotropy.

For Groups $C$ and $D$, where loading would normally be assumed to occur, the existence of plastic strains after the application of torque is verified. Again the value of $G_{i}$ for these groups is about $\frac{1}{2}$ of $G_{0}$, contrary to the results predicted by isotropic theories of plasticity.

It is the opinion of the present authors that the experimental results given here are explained in the main by the presence of initial and strain-hardening anisotropy and the existence of corners on the yield loci of the material. It may, of course, be possible that other factors, such as strain rate and time effects, grain size, homogeneity of stress state, and machining of specimens may have infiuenced the results. However, these effects are felt to be small.

Aside from the initial value of the shear modulus $G_{i}$ and its consequences discussed above, the general trend of the results agrees favourably with those of other investigators (Budiansixy, Dow, Peters and Shepherd 1951; Morrison and ShePherd 1950). Comparisons between experimentally determined plastic strains with those predicted by simple incremental and total strain theories are not plotted in Fig. 7-16 since, in view of the discussion concerning the effects of anisotropy and the yield surface, such comparisons appear to be useless.

\section{Acknowledgment}

The authors wish to express their appreciation to Messrs C. W. BeADLE and G. A. Shifris, Research Assistants in Engineering Mechanics, for thier valuable assistance, both in the improvement of the extensometer and other equipment and in the running of tests.

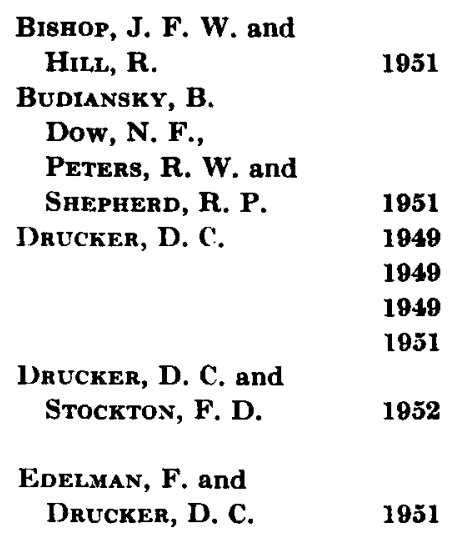

\section{References}

Phil. Mag., 42, 414 and 1298.

Proc. First U.S. Nat. Cong. Appl. Mech., 503.

J. Appl. Mech., 16, 349.

Proc. First Symp. Appl. Math., 1, 181.

J. Colloid Science, 4, 220.

Proc. First U.S. Nat. Cong. Appl. Mech., 487.

To appear in Proc. Soc. Exp. Stress Anal. ; also ONR Tech. Rept. 68, Brown University.

J. Franklin Inst., 251, 581. 
80

HrLL, R.

Moone, R. L.

Mornison, J. L. M. and SHepkerd, W. M.

Prager, W.

Peters, R. W., Dow, N. F. and Batdorf, S. B. Stockton, F. D.
P. M. NAGHd and J. C. Howley

1950 Mathematical Theory of Plasticity (Clarendon Press)

$1043 N$ NACA TN, 878.

1050 Proc. Inst. Mech. Eng., 163, 1.

1048 J. Appl. Mech., 15, 220.

1948 NACA TN, 1501.

1040 J. Appl. Phys., 20, 235.

1049 Proc. Soc. Exp. Stress Anal., 7, 127.

1953 ONR Tech. Rept., 88, Brown University. 